\title{
Some rock engineering aspects of multi- reef pillar extraction on the Ventersdorp Contact Reef
}

\author{
by J.C. Esterhuyse** and D.F. Malan ${ }^{\dagger}$
}

\begin{abstract}
Synopsis
Mining in the Carletonville area of the Witwatersrand Basin predates 1934. Owing to the depletion of higher grade ore, the current activities focus increasingly on the extraction of lower grade secondary reefs as well as remnant extraction. Of particular interest is multi-reef remnant extraction. Numerical modelling was conducted to investigate some rock engineering aspects of remnants being understoped on a secondary reef horizon. An analysis of the stress evolution in the middling between two reef horizons indicated that a zone of high major and low minor principal stress develops between the two reefs. This indicates a high risk of violent shear failure. Some pillars were nevertheless successfully understoped in the past and a study was conducted to better understand this phenomenon. An 'extended' energy release rate concept introduced by Napier and Malan (2014) proved to be useful for investigating this problem. It was found that bedding planes and lithology appears to play a role in the stable dissipation of energy in multi-reef remnant geometries. The study indicated that the stope convergence and the various energy components are affected by the presence, position, and properties of a bedding plane. The energy solutions are complex and sometimes counterintuitive. Care should be exercised when modelling specific cases. The modelling was nevertheless valuable as it indicated that energy dissipated on weak layers may reduce the risk of violent failure in a multi-reef mining scenario. Additional work is required to investigate if crushing on the reef plane plays a prominent role when mining these remnants.

Keywords

deep-level mining, remnant extraction, understoping, multi-reef mining, energy dissipation, numerical modelling.
\end{abstract}

\section{Introduction}

To extend the lives of the Witwatersrand gold mines, work is being conducted to include a larger number of remnants and pillars in the reserve base of the mines. According to Jager and Ryder (1999), a remnant is an unmined block of ground surrounded by extensive mining. Remnants are typically left because of adverse or difficult mining conditions caused by geological structures, poor ground conditions, low grade, or rockburst damage (Durrheim, 1997). In contrast, pillars are typically the result of rock engineering designs to control energy release rates (ERR) and seismicity. During the early 1900s, remnants formed by the practice of scattered mining layouts had a significant effect on seismicity. Numerous task teams were appointed during this period. As the industry expanded, the severity of rockbursting increased and the research was formalized after the 1960s. Various recommendations were made and many of these are still used as best practice today (e.g. Jager and Ryder, 1999).

In contrast, a literature survey indicated that almost no recommendations are available for multi-reef mining and multi-reef remnant scenarios. A large number of reefs are present within the Witwatersrand Basin. As an example, the Central Rand goldfield has three predominant reefs, namely the Main Reef, Main Reef Leader, and South Reef. These reef bands are situated in close proximity to one another. Multi-reef mining is therefore common within the Basin. Plans dating from 1946 show mined areas on the Main Reef group with middlings in the order of a few metres (Riemer and Durrheim, 2011). Most of the knowledge available on multi-reef mining is based on empirical data and past experience. According to Jager and Ryder (1999), designing layouts or support for multi-reef mining should always be approached as a unique problem. Such designs require the consideration of additional variables, namely middling, the effect of pillars and remnants, and the influence of surrounding rock types. There are two sub-categories of multi-reef mining: simultaneous and subsequent extraction. Each category would involve a different set of considerations for safe extraction of an area.

Du Plessis and Talu (1997) described multi-reef pillar mining in a deep-level gold mine in the West Wits Line. The paper highlights the influence of rock type and middling. The authors describe the problems encountered when the middling was too small as this caused the stopes to collapse. When destressing of Ventersdorp Contact Reef (VCR)

* Sibanye Gold, South Africa

+ Department of Mining Engineering, University of Pretoria, South Africa.

(c) The Southern African Institute of Mining and Metallurgy, 2018. ISSN 2225-6253. Paper received Dec. 2017; revised paper received Apr. 2018. 


\section{Some rock engineering aspects of multi-reef pillar extraction on the Ventersdorp Contact Reef}

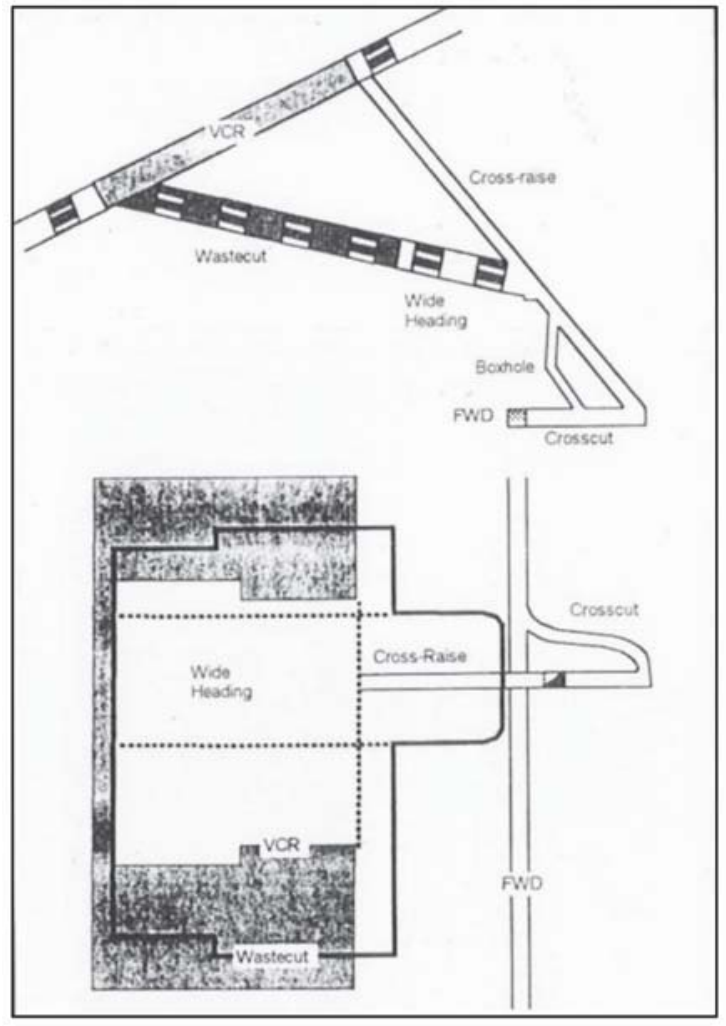

Figure 1-The Hennings method of mining a waste cut below a VCR pillar (after du Plessis and Talu, 1997)

pillars was done by mining on the lower Kloof Reef, poor ground conditions were encountered if the middling was too small. It was also a problem when the VCR mining followed too far behind the Kloof Reef faces. The strata control problems encountered were probably a result of the area being de-stressed with the associated tensile zone above the stope. VCR pillar mining was sometimes also done by first mining a de-stressing waste cut (Figure 1). If no waste cut was carried, the closure rates within the VCR stope were very high, the hangingwall deteriorated, and even mined itself out in front of the reef face (du Plessis and Talu, 1997).

Some historical work was conducted on the platinum mines with specific reference to multi-reef room-and-pillar mining in shallow conditions. Napier and Malan (2008) illustrated the value of the TEXAN modelling code for analysing multi-reef mining conditions. Superimposing of pillars and bord stability are key considerations in the platinum bord-and-pillar operations. This is also the case in coal mining (van der Merwe and Madden, 2002), where the general rule is that pillars should be superimposed if the middling is smaller than 0.75 times the pillar centre distance. The typical problems experienced on the platinum mines and coal mines are, however, different to those of the deep-level gold mines, owing to different layouts. In general, in the gold mines, a significant reduction in the vertical stress component is achieved once a particular area is extensively mined. The change in the stress field will affect the rock mass and the fracturing patterns when mining a secondary reef in close proximity to the initial mining, thereby increasing the support requirements. Other associated problems include bed separation when understoping or complete closure and stress-regeneration when overstoping (Hustrulid, 2001).

Based on the experience of the authors in the deep gold mines, it appears that some reef types are easily under- or overstoped. The classical example is that the VCR is easily understoped by the Kloof or Libanon Reefs. In contrast, when highly stressed Carbon Leader Reef abutments are overstoped by the Middelvlei Reef (a middling of approximately $50 \mathrm{~m}$ ), seismic events of magnitude M3.0 are a common occurrence. No proper scientific study on this phenomenon has been done to date. This paper is a first attempt to better understand this under- or overstoping process. It should be noted that in the modelling discussed below, only off-reef failure on bedding planes was allowed and not on the reef plane. This approach may be questioned as local researchers have conducted extensive work in the last few years on the use of a limit equilibrium model to simulate on-reef failure and the associated energy changes. Readers can find examples of this work in Napier and Malan $(2012,2014)$. The 2014 paper is particularly interesting as examples such as average energy released per unit area mined for a pillar holing geometry, where the on-reef material was allowed to crush, are illustrated. With regard to the calibration of this model, Malan and Napier (2018) illustrated that the model can give good qualitative agreement with historic closure profiles collected in the South African mining industry. Work indicated that element size plays a role and the TEXAN code now includes a sub-element construction algorithm that allows the moving edge of the fracture zone to be simulated in partially fractured elements.

The work in this paper is presented to illustrate that a mechanism to safely dissipate the energy stored in the rock mass in deep-level mining is required to succesfully under- or overstope remnants. As dwindling production in the gold mines increases the pressure on companies to mine old stabilizing pillars, this work is of importance to indicate that sufficient care should be taken with the attempted overstoping of these stabilizing pillars. A case study is also presented of a VCR stope being understoped by mining on the Libanon Reef.

\section{Simulation of a multi-reef mining problem}

Jager and Ryder (1999) indicated that it is difficult to determine the parameters influencing multi-reef mining. Numerical modelling is therefore valuable in this regard. Napier and Malan (2007) illustrated that the TEXAN displacement discontinuity code is useful for simulating multi-reef environments. A difficulty with displacement discontinuity codes is that numerical instability can be experienced when the reefs are in close proximity. This is particularly problematic if the reefs are closer than three element diameters when constant strength elements are used. This problem can be overcome if higher order elements are used. Maritz (2014) and Maritz and Malan (2012) also used the TEXAN code to simulate multi-reef environments. TEXAN can currently solve 2D and 3D problems with multiple interacting tabular reef planes and planar fault planes. The rock is assumed to be elastic and isotropic. of particular interest is the ability of the code to use higher order elements. This allows for the simulation of closely spaced reefs and accurate calculation of the tensile zones above the stopes. 


\section{Some rock engineering aspects of multi-reef pillar extraction on the Ventersdorp Contact Reef}

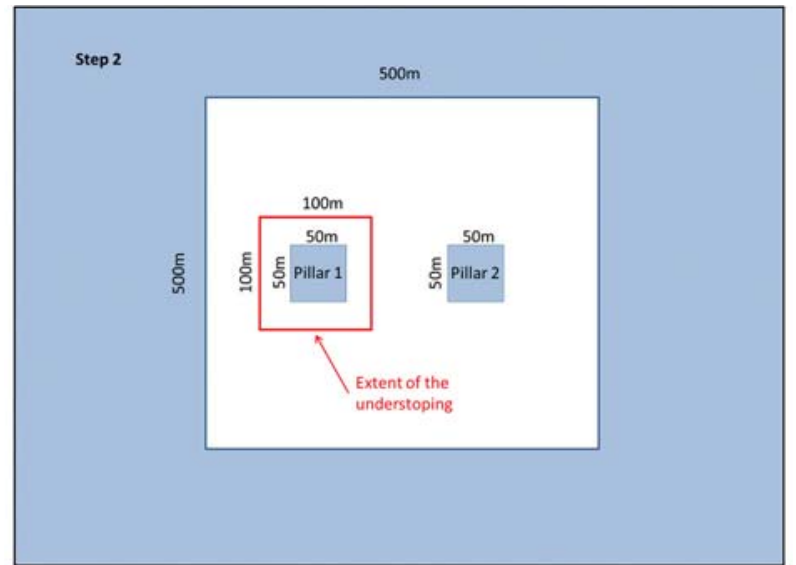

Figure 2-Stope layout used for the numerical simulation
To investigate the mechanism of understoping for the current study, a simplified geometry was used for the initial simulations. This is shown in Figure 2. It consists of a mined VCR stope of $500 \mathrm{~m} \times 500 \mathrm{~m}$ with two pillars remaining. Pillar 1 was incrementally understoped on a secondary reef plane (Libanon Reef). The full $100 \mathrm{~m}$ face length of the Libanon Reef was mined in steps during this incremental understoping process. Napier and Malan (2014) explored the difference between a uniform advance front and a wedgeshaped mining shape when mining in high-stress conditions. These options were not explored in this current paper. For the initial run, the middling was $25 \mathrm{~m}$. The stope was simulated with no dip and the depth was $2000 \mathrm{~m}$. Although only one pillar was understoped, a second pillar was included in the simulation to illustrate the increase of stress on this second pillar after the first pillar was extracted (not shown in this

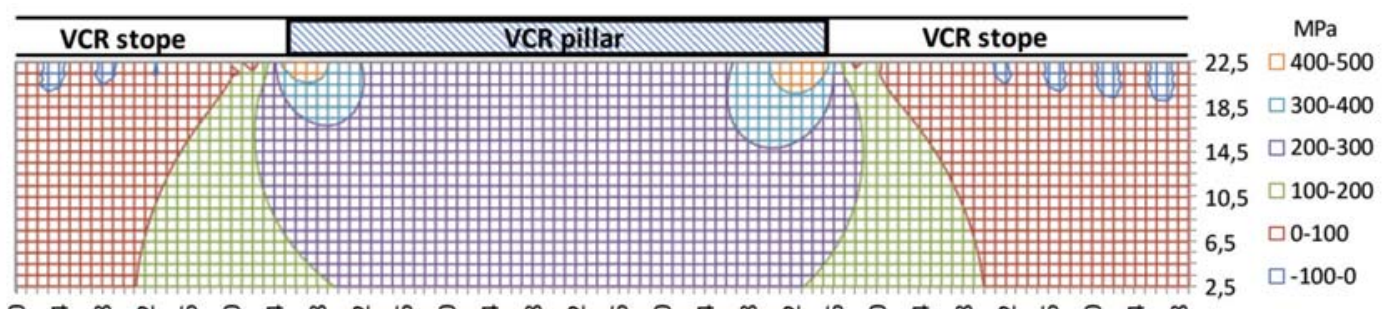

రి ఫ

Figure 3-Major principal stress below the VCR pillar 1 prior to any mining on the Libanon Reef. The region of very high principal stress is found at the edge of the pillar, but is confined to localized regions. The stress convention for plotting these graphs is that compressive stresses are positive. The legend indicates tensile stress from $-100 \mathrm{MPa}$ to $0 \mathrm{MPa}$ and compressive stress from $0 \mathrm{MPa}$ to $500 \mathrm{MPa}$
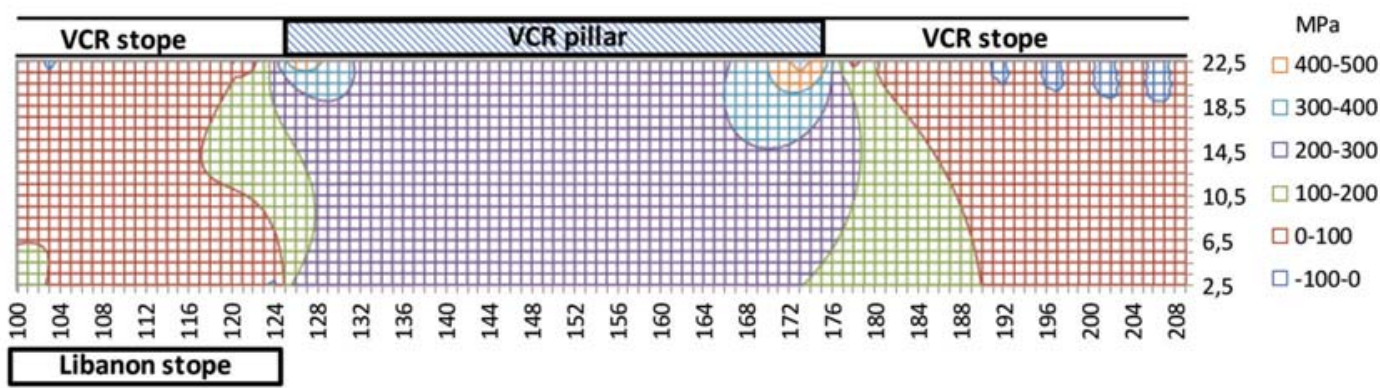

$\square-100-0$

Figure 4-Major principal stress below the VCR pillar when the Libanon Reef stope is below the first pillar abutment. The full $100 \mathrm{~m}$ face length of the Libanon was mined during each increment. The disruption of the stress field is minor at this stage. The stress convention for plotting these graphs is that compressive stresses are positive. The legend indicates tensile stresses from $-100 \mathrm{MPa}$ to $0 \mathrm{MPa}$ and compressive stresses from $0 \mathrm{MPa}$ to $500 \mathrm{MPa}$

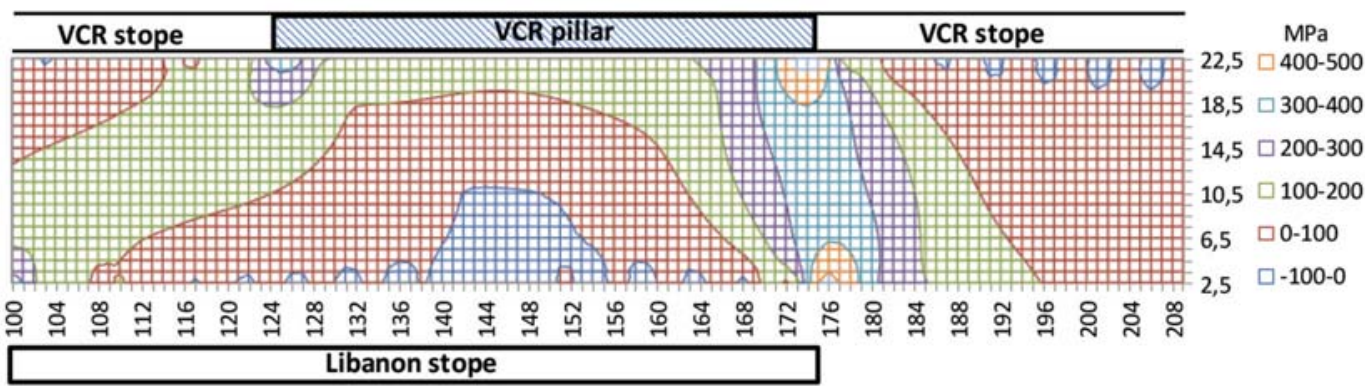

Figure 5-Major principal stress below the VCR pillar when the Libanon Reef stope face is halfway below the VCR pillar. Note the region of very high principal stress between the edges of the two stopes. The stress convention for plotting these graphs is that compressive stresses are positive. The legend indicates tensile stresses from $-100 \mathrm{MPa}$ to $0 \mathrm{MPa}$ and compressive stresses from $0 \mathrm{MPa}$ to $500 \mathrm{MPa}$ 


\section{Some rock engineering aspects of multi-reef pillar extraction on the Ventersdorp Contact Reef}

paper). The parameters used in the model were a Young's modulus of $70 \mathrm{GPa}$, Poisson's ratio of 0.2 , k-ratio of 0.5 , and a vertical stress increase of $0.027 \mathrm{MPa} / \mathrm{m}$. Owing to the small middling between the two reefs, a $2 \mathrm{~m}$ grid size was used in the model.

To understand the process of understoping, an analysis of the incremental stress evolution in the middling between the two reef horizons was conducted. The plots in Figures 38 illustrate a section through the centre of pillar 1 and the stresses between the VCR and Libanon Reef horizons. Note that a zone of very high major principal stress forms between the reefs (Figures 5 and 6). The minor principal stress is significantly reduced during these steps (Figure 8) and the risk of shear failure between the reefs is therefore high.

\section{The extended energy release concept}

Ryder and Jager (2002) provide an extensive treatise on the ERR concept. They define ERR as the spatial rate of release of 'unaccounted-for' energy per $\mathrm{m}^{2}$ mined. Since the 1960s, it has been one of the key criteria in the design of deep-level gold mine layouts in South Africa (see e.g. Salamon, 1984; Napier, 1991). ERR is considered as a measure of stress concentration and therefore underground conditions at the mining faces. Displacement discontinuity numerical methods are well suited to calculate ERR values for irregular mining layouts.

ERR has practical shortcomings as a measure of the rockburst hazard. Its most significant drawback is that no

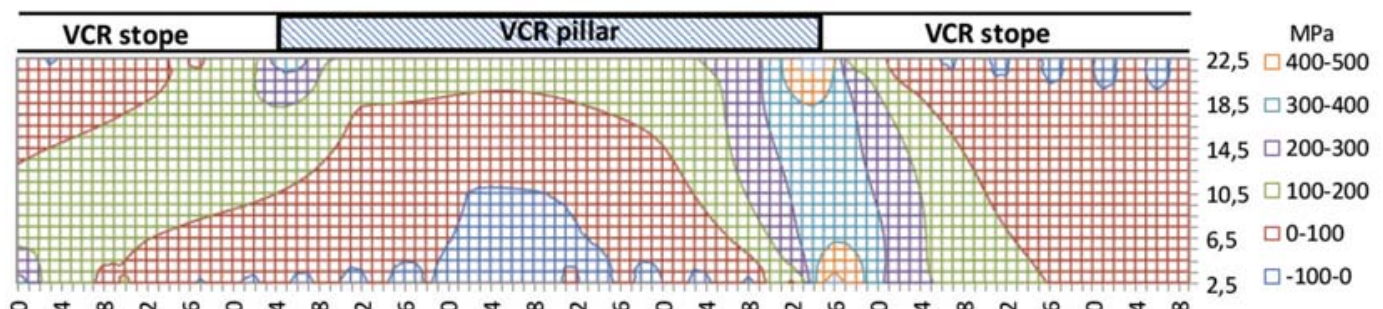

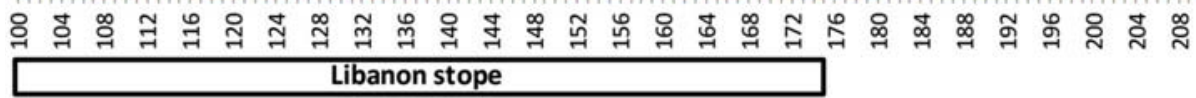

Figure 6-Major principal stress below the VCR pillar when the Libanon Reef stope position is below the second VCR abutment. The region of very high principal stress between the edges of the two stopes persists at this stage. The average stress in a $3 \mathrm{~m}$ wide vertical zone between the edges of the two stopes is $395 \mathrm{MPa}$. The stress convention for plotting these graphs is that compressive stresses are positive. The legend indicates tensile stresses from $-100 \mathrm{MPa}$ to $0 \mathrm{MPa}$ and compressive stresses from $0 \mathrm{MPa}$ to $500 \mathrm{MPa}$

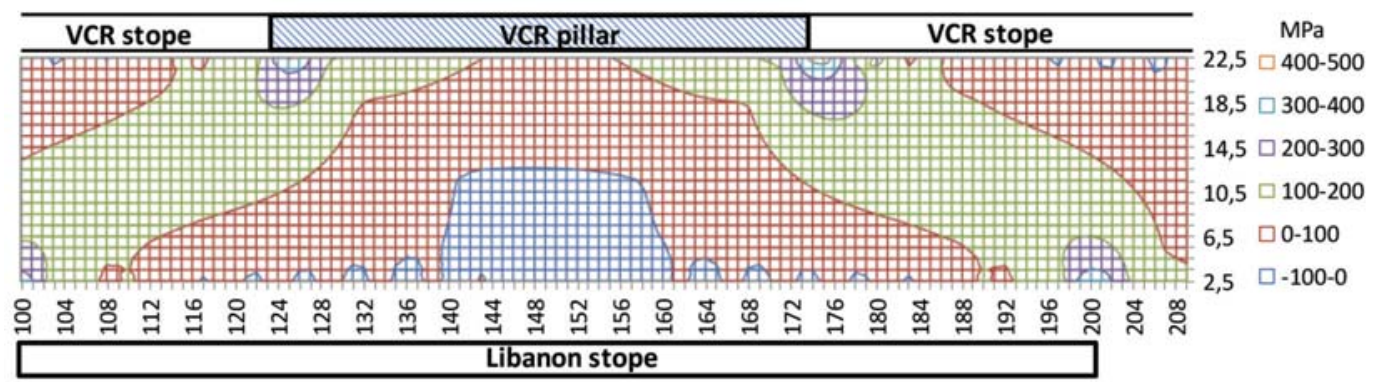

Figure 7-Major principal stress below the VCR pillar when the Libanon Reef stope mined $25 \mathrm{~m}$ past the second VCR pillar abutment. Note that a large tensile zone has formed above the centre of the Libanon stope. The stress convention for plotting these graphs is that compressive stresses are positive. The legend indicates tensile stresses from $-100 \mathrm{MPa}$ to $0 \mathrm{MPa}$ and compressive stresses from $0 \mathrm{MPa}$ to $500 \mathrm{MPa}$

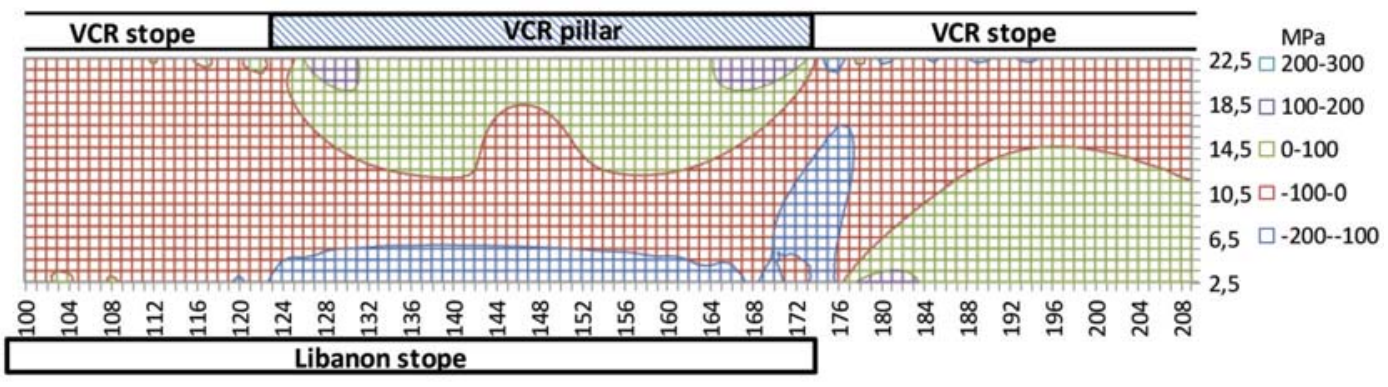

Figure 8-Major principal stress below the VCR pillar when the Libanon Reef stope position is below the second VCR abutment. The region of tensile minor principal stress between the edges of the two stopes in conjunction with the high major principal stress shown in Figure 6 will result in shear failure between the reefs. The stress convention for plotting these graphs is that compressive stresses are positive. Note that the legend is different for this one graph. It indicates tensile stresses from $-200 \mathrm{MPa}$ to $0 \mathrm{MPa}$ and compressive stresses from $0 \mathrm{MPa}$ to $300 \mathrm{MPa}$ 


\section{Some rock engineering aspects of multi-reef pillar extraction on the Ventersdorp Contact Reef}

dissipative mechanisms are incorporated into the criterion to allow for the effects of face crushing, failure, and shear on discontinuities. To address this shortcoming, Napier and Malan (2014) investigated an extended criterion to include an energy dissipation term. The basis of this work was a study by Napier (1991) to compute energy changes in an elastic rock mass that contains an arbitrary number of fractures. The key aspects of this approach are illustrated below.

In the extended criterion, the 'energy release' increment, $\Delta W_{A}$ represents the difference between the incremental work done by gravity forces acting on the rock mass, $\Delta W$, and the incremental change in the strain energy, $\Delta U$, when the excavation boundary is extended during a mining step. $\Delta W_{A}$ is therefore given by:

$$
\Delta W_{A}=\Delta W-\Delta U
$$

If the incremental area mined is designated by $\triangle A$ then the 'classical' energy release rate is defined to be:

$$
E R R=\lim _{\Delta A \rightarrow 0} \Delta W_{A} / \Delta A
$$

These ERR values are computed for tabular mine layouts using programs such as MINSIM (Plewman, Deist, and Ortlepp, 1969; Deist, Georgiadis, and Moris, 1972; Ryder and Napier, 1985), which uses the displacement discontinuity boundary element method. An enhanced criterion is proposed by Napier and Malan (2014), which include an energy dissipation term $\Delta W_{D}$. Napier and Malan (2014) proposed that 'the traditional energy release rate design criterion (ERR) is re-interpreted as a metric of extraction sequence stability by including explicit energy dissipation mechanisms in the computational framework. 'A general measure of incremental mining stability, designated as $\Delta W_{R}$, can be defined as follows:

$$
\Delta W_{R}=\Delta W_{A}-\Delta W_{D}
$$

and by inserting Equation [1]:

$$
\Delta W_{R}=\Delta W-\Delta U-\Delta W_{D}
$$

The incremental stability measure or 'extended' ERR, as defined by Equation [4], is associated with an incremental change to the excavation shape and may, in addition, include released energy from explicitly modelled fractures or bedding planes.

\section{The effect of a weak discontinuity plane}

Inelastic rock behaviour cannot be simulated in displacement discontinuity codes except for discontinuities, such as bedding planes and fractures, that can be explicitly included in the model. The approach followed was to use a layout geometry similar to that of Figure 2, and including a bedding plane parallel to the reef planes. The numerical model used a $5 \mathrm{~m}$ element grid with a $30 \mathrm{~m}$ middling between the reefs. A bedding plane was introduced $15 \mathrm{~m}$ from the excavations at various positions (above, below, and between the reefs). The discontinuity parameters (friction and cohesion) were selected to simulate a 'weak' or a 'strong' bedding plane. The values used were arbitrary values on the extremes of the scale. The ERR was calculated by using Equation [4] to take energy dissipated by the bedding plane into account. The objective was to provide some insight as to why understoping can be successfully used in some areas to extract pillars, but not in others.

The energy components during the understoping process are illustrated in Figures 9 and 10. The cumulative released energy $\Delta W_{R}$ for different bedding plane positions is plotted in Figures 9 and 10. For the 'intact' case, no bedding plane was included in the run. From these figures it can be seen that the cumulative released energy for a bedding plane situated in the hangingwall of the VCR or footwall of the Libanon is less than that if no bedding plane is present. This effect is more pronounced in Figure 10 for the weak bedding plane. This illustrates that if an appropriate mechanism exists to dissipate energy in a stable manner, the understoping process will be less hazardous than that predicted by the elastic model in Figures 4 to 7 . It is also evident that a

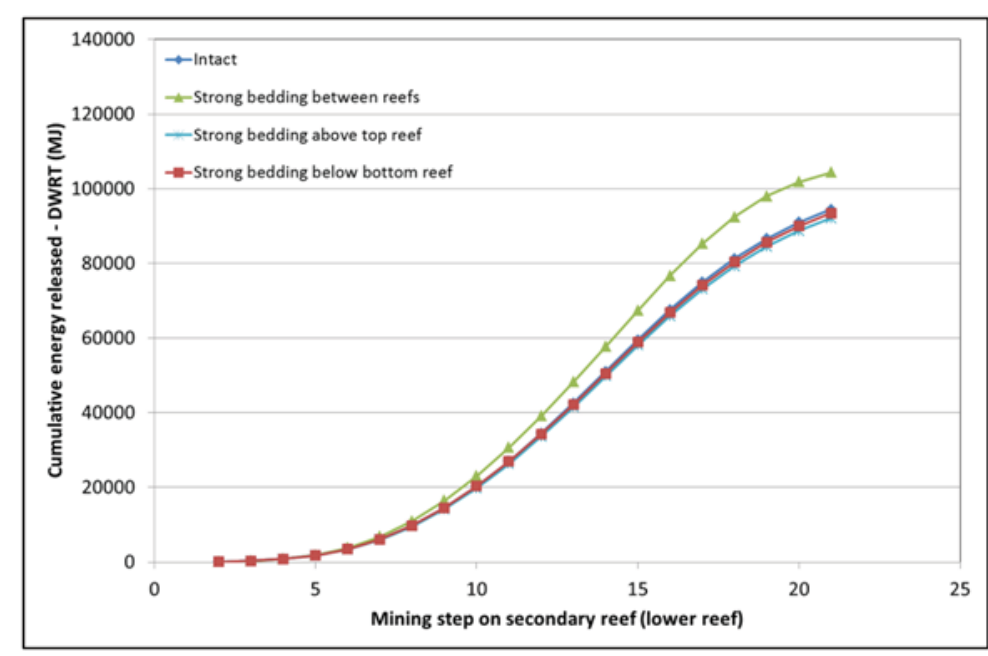

Figure 9-Cumulative released energy during the understoping process for a $30 \mathrm{~m}$ middling. DWRT is the TEXAN notation for $\Delta W_{R}$. This is the 'extended' ERR, and higher values would indicate more hazardous conditions. 'Intact' in the legend refers to the case where no bedding plane was present 


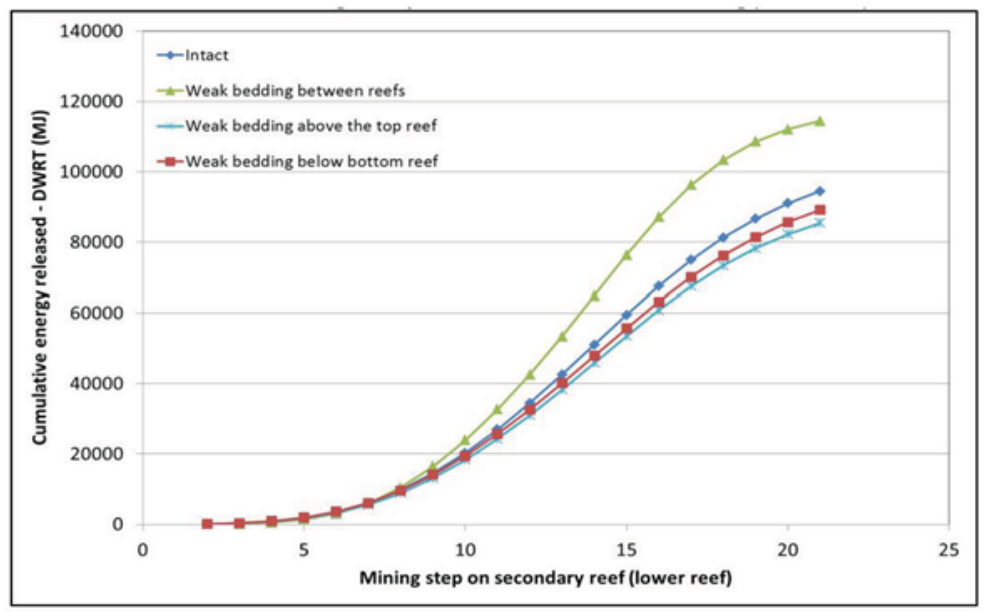

Figure 10-Cumulative released energy during the understoping process for a $30 \mathrm{~m}$ middling. DWRT is the TEXAN notation for $\triangle W_{R}$. This is the 'extended ERR', and higher values would indicate more hazardous conditions

bedding plane between the two reef horizons has a much higher released energy component. This is the result of the bedding plane in this position increasing the convergence in the stope and causing a much higher overall work, $\Delta W$, component.

From the previous results, it appears that a weak bedding plane, if correctly positioned, reduces the energy released at the advancing face and therefore decreases the risk when understope mining. Care should, however, be exercised when interpreting the energy results as the bedding plane between the reefs seems to increase the energy released. To investigate this, the dissipative energy component, $\Delta W_{D}$, and the work done, $\Delta W$, are shown in Figures 11 and 12. The bedding plane between the reefs substantially increases the energy dissipated on the bedding plane (Figure 11), but it cannot compensate for the increase in the total work done on the system (Figure 12). This explains the higher $\Delta W_{R}$ components in Figures 9 and 10.

A table was compiled showing the average closure on the two reef planes and the associated energy components for the four scenarios. Table I shows values for the last mining step. It can be seen that the energy dissipated for the intact scenario is zero, due to the absence of a bedding plane. By comparing the closure and the cumulative work done, it can be seen that the components are related. For the weak bedding between the reefs, the closure is substantially higher and the result is the largest cumulative work done. For this case, the energy dissipated is also the highest, but it cannot compensate for the greater cumulative work done and therefore this presents a higher released energy and the greatest risk. An unexpected result can be seen from the table, as a large amount of energy was dissipated with the introduction of a bedding plane between the reefs; this is, however, offset by the total work done. In simple terms, this would mean that the system would have more energy available for effect releases such as seismicity or fracturing. From the table the shear fracturing is expected to be 10- to 100 -fold that of situations where the bedding plane is located above or below the reefs.

Future work using different codes that can simulate rock failure is required to further investigate the effect of energy dissipation by thick weak layers or fracturing. This work also needs to be extended by allowing failure to occur on the reef plane.

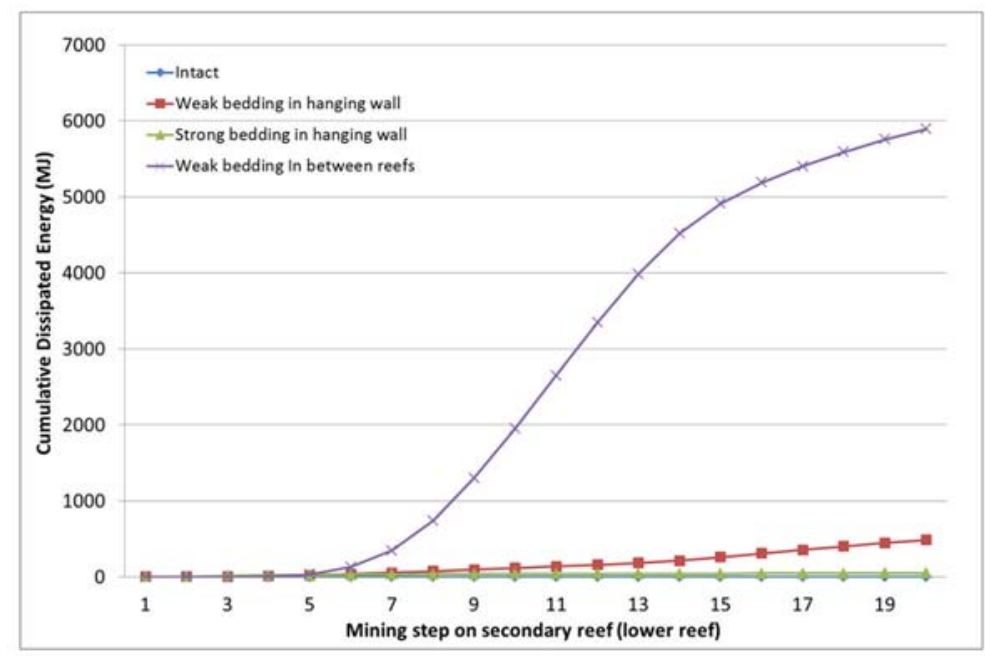

Figure 11-Cumulative dissipated energy during the understoping process for a $30 \mathrm{~m}$ middling. This is parameter $\Delta W_{D}$ in Equation [4] 


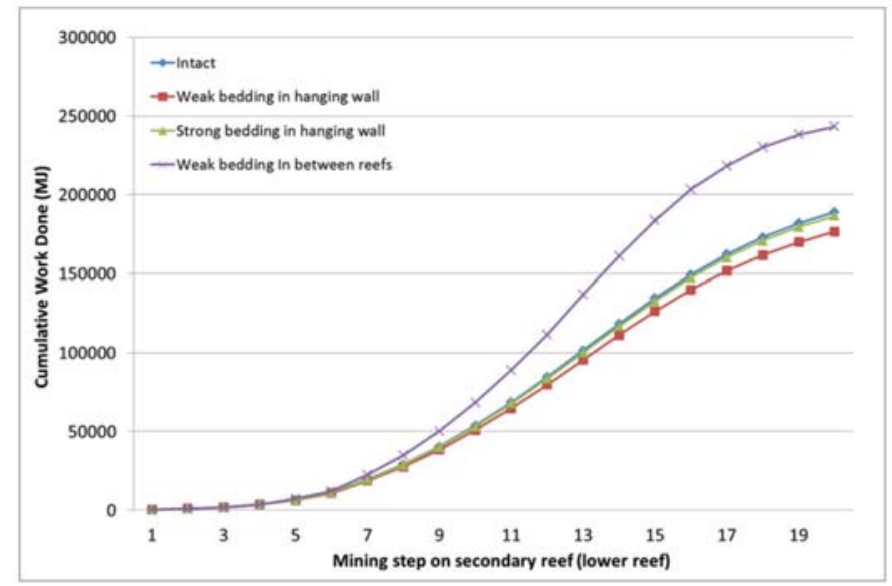

Figure 12-Cumulative work done during the understoping process for a $30 \mathrm{~m}$ middling. This is parameter $\Delta W$ in Equation [4]

\section{Table I}

Energy components for a geometry with a $30 \mathrm{~m}$ middling, calculated for the last step. Note that the cumulative energy dissipated is that dissipated on the bedding plane and is basically the work done during slip on the bedding plane

\begin{tabular}{|c|c|c|c|c|c|c|}
\hline & $\begin{array}{c}\text { Calculated } \\
\text { average } \\
\text { closure } \\
\text { VCR } \\
(\mathrm{mm})\end{array}$ & $\begin{array}{l}\text { Calculated } \\
\text { average } \\
\text { closure } \\
\text { Libanon } \\
\text { (mm) }\end{array}$ & $\begin{array}{c}\text { Cum. } \\
\text { released } \\
\text { energy } \\
\text { (DWRT) } \\
\left(\Delta W_{R}\right)\end{array}$ & $\begin{array}{c}\text { Cum. } \\
\text { work } \\
\text { done } \\
\text { (DWT) } \\
(\Delta W)\end{array}$ & $\begin{array}{c}\text { Cum. } \\
\text { strain } \\
\text { energy } \\
\text { (DUT) } \\
(\Delta U)\end{array}$ & $\begin{array}{c}\text { Cum. } \\
\text { energy } \\
\text { dissipated } \\
\text { (DWDST) } \\
\left(\Delta W_{D}\right)\end{array}$ \\
\hline Intact & 284.17 & 156.08 & 94441 & 188893 & 94452 & 0 \\
\hline $\begin{array}{l}\text { Weak bedding in } \\
\text { hangingwall }\end{array}$ & 284.45 & 154.19 & 85441 & 176515 & 90587 & 488 \\
\hline $\begin{array}{l}\text { Strong bedding in } \\
\text { hangingwall }\end{array}$ & 285.04 & 150.16 & 92107 & 186533 & 94374 & 52 \\
\hline $\begin{array}{l}\text { Weak bedding } \\
\text { between reefs }\end{array}$ & 289.16 & 173.73 & 114363 & 243225 & 122971 & 5892 \\
\hline
\end{tabular}

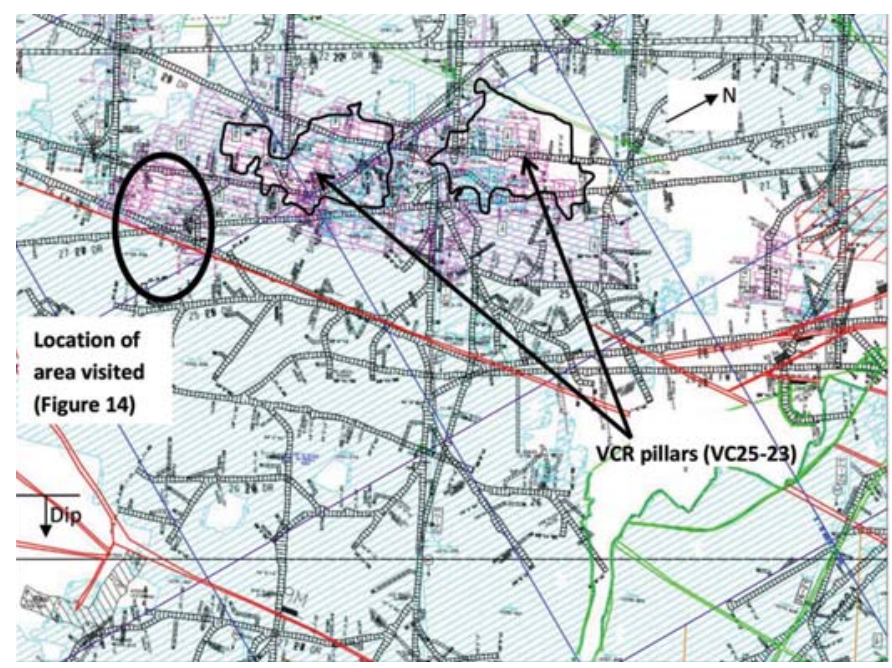

Figure 13-Locality plan view of the VC25-23 area. The VCR pillars are indicated by the black outline. The blue areas are mined VCR and the purple is mining on the Libanon Reef

\section{Back-analysis of a multi-reef remnant}

A back-analysis was conducted on an actual VCR remnant understoped by a Libanon Reef stope (Figures 13 and 14). The particular remnant is located to the southwest of this particular shaft where the LI25-23A stope is overlain by the
C25-23 stope. The middling between the two reefs is $15 \mathrm{~m}$. Both the VCR and Libanon reefs are a quartzitic conglomerate; the immediate footwall of the VCR is quartzite, whereas the footwall of the Libanon is shale. The hangingwall of the VCR consists of weak Western Area Formation (WAF) lava. 


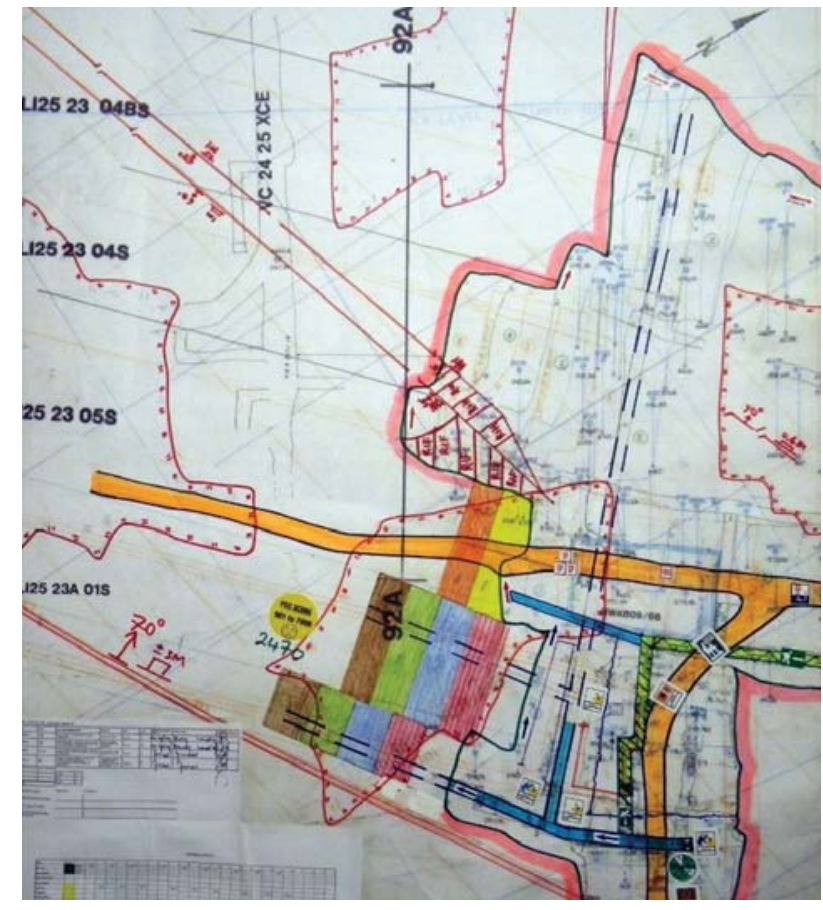

Figure 14-A stope sheet of the LI25-23A area. This area was visited and the photographs shown in Figures 18 to 21 were taken in this area. The VCR pillars are shown by the red outlines (not visible in Figure 13). The planned mining on the Libanon Reef at the time this was photographed is shown by coloured rectangular blocks

The mining in the area commenced on the Libanon Reef to understope the VCR remnant (Figure 15). This was done to destress the VCR remnant and allow for its eventual safe extraction. Very little stoping occurred on the Libanon Reef in this area prior to the commencement of the understoping. The main VCR target area $\left(17000 \mathrm{~m}^{2}\right)$ was two pillars on either side of a raise with mining on all sides. According to the mine plans, no major geological structure is present in this block of ground. A fault and dyke are present in the general vicinity, but these structures were extensively stoped through in the past.

The historical seismicity in the area (Figures 16 and 17) shows the cumulative seismic moment. Figure 17 is divided into four distinct periods of mining. Some of the Libanon mining occurred in the highly stressed ground below the VCR pillars. The cumulative seismic moment for this part of the mining nevertheless does not appear higher than for the destressed VCR mining. Ideally, the seismic moment released during the VCR mining must be compared to the mining of VCR pillars in this area that were not destressed. This data is unfortunately not readily available to the authors. The experience of the production personnel at the shaft indicated that VCR pillars that were not destressed could not be mined safely, owing to high level of seismicity encountered at these sites. This observation needs to be further investigated.

To identify possible mechanisms of energy dissipation, an underground visit was conducted to this site. Figures 18 to 21 illustrate the typical underground conditions in the Libanon Reef stope. Figure 18 indicates the in-stope conditions with a solid hanging- and footwall. Surprisingly, almost no fracturing could be seen in the face of the Libanon Reef stope, even though it was at the position immediately below the VCR pillar. This should be considered in future studies regarding the role played by on-reef crushing. In some areas, the prominent bedding planes in the hangingwall of the Libanon Reef could be seen (Figure 19). Figure 20 depicts the conditions between the two reef horizons as seen some distance up an orepass being developed. Some evidence of shear between the reefs was observed (Figure 20), and this may be evidence of the mechanism described above. The weak nature of the shale in the footwall is probably also playing an important role, but evidence of this could not be seen during the visit. Also, the unravelling of the Libanon Reef hangingwall was very prominent in the back area where the understoping was completed (Figure 21). This can possibly be attributed to the tensile zone above the stopes owing to the destressing process. These observations seem to support the conditions expected from the modelling results.

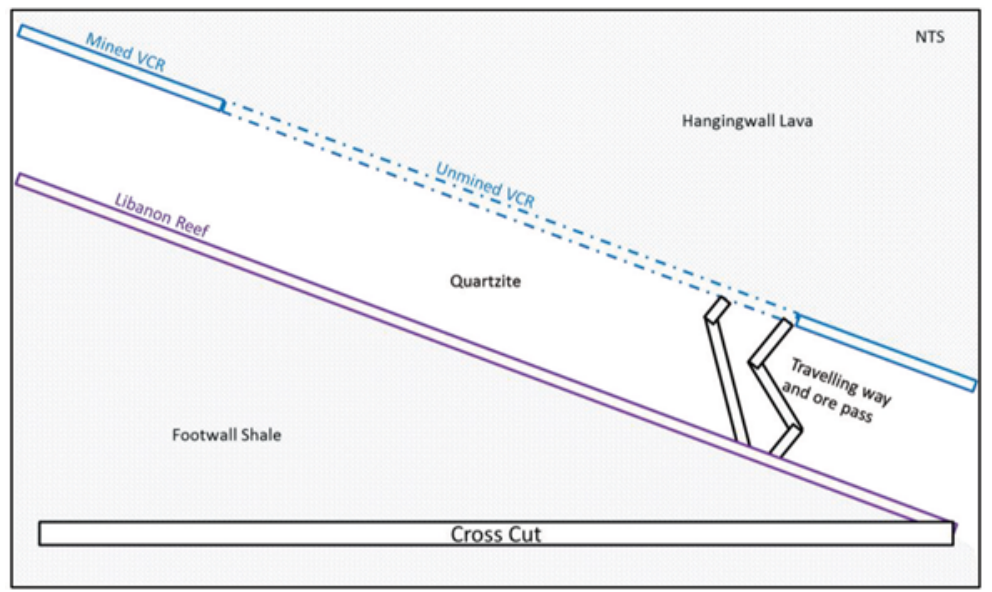

Figure 15-Simplified section through the VC25-23 depicting the two reef bands and the inclined accessways 
Some rock engineering aspects of multi-reef pillar extraction on the Ventersdorp Contact Reef

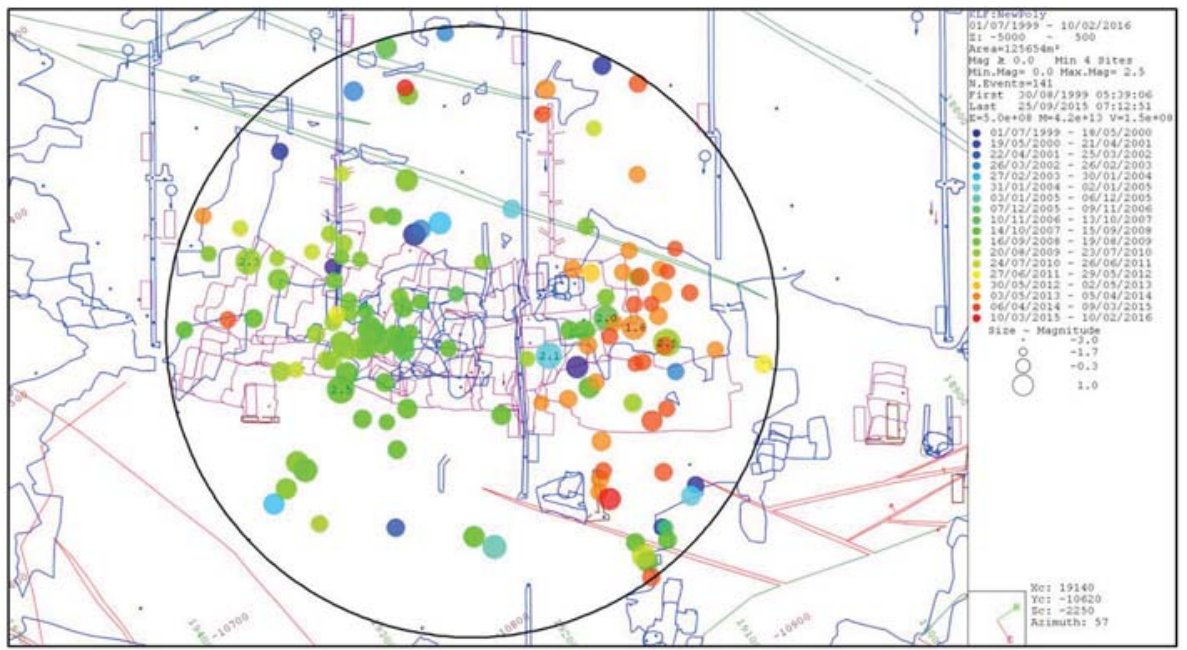

Figure 16-Plot of all events greater than ML0.0 in a $300 \mathrm{~m}$ radius. This was for the period from July /1999 to 10 February 2016

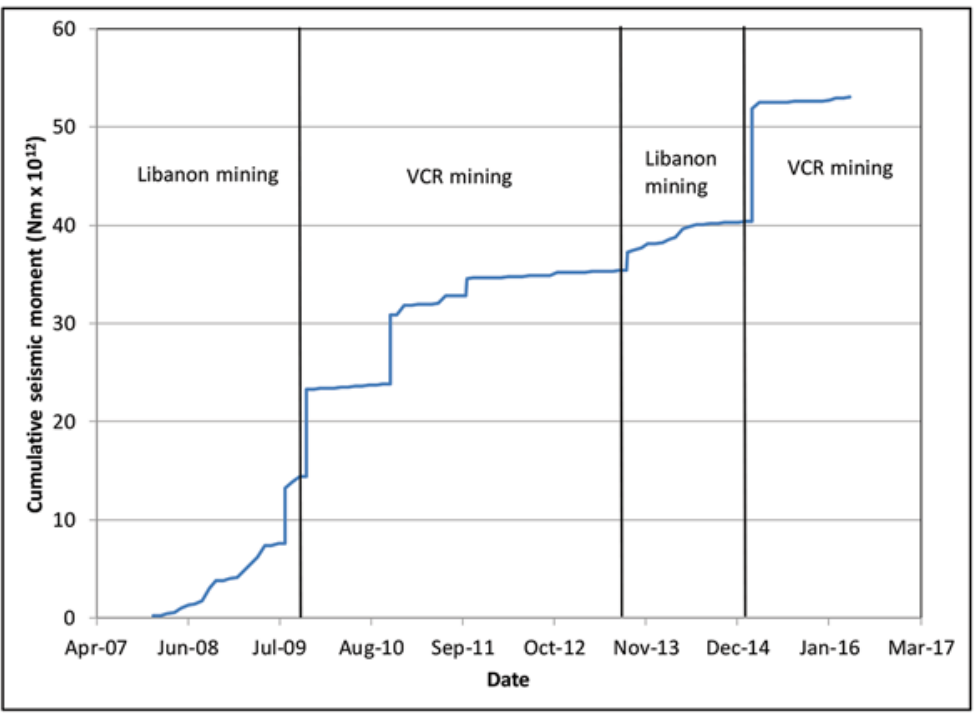

Figure 17-Calculated cumulative seismic moment observed in the VC25-23 area over a period of 8 years

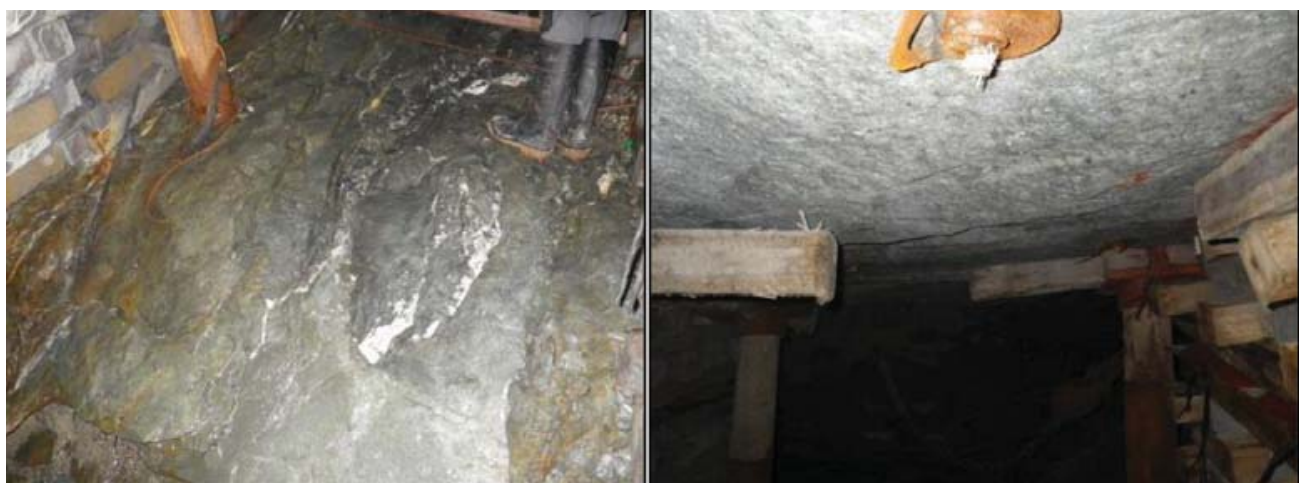

Figure 18-Condition of the shale footwall (left) and quartzite hangingwall (right) in the LI25-23 Libanon Reef stope 
Some rock engineering aspects of multi-reef pillar extraction on the Ventersdorp Contact Reef

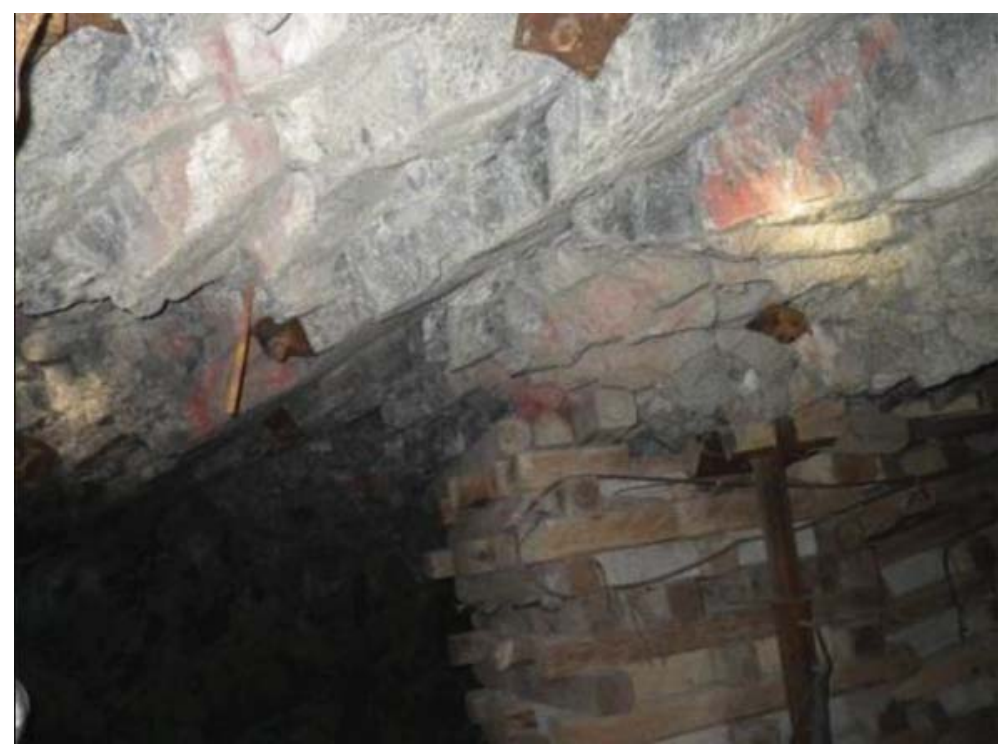

Figure 19-Condition of the quartzite hangingwall, where the bedding planes were exposed in the back area of the LI25-23 Libanon Reef stope

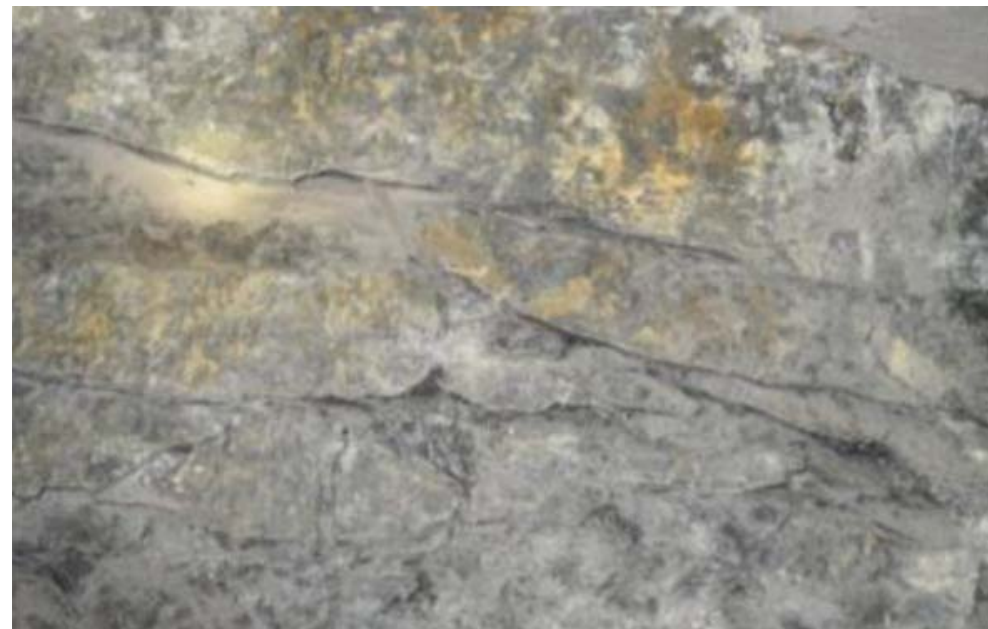

Figure 20-Condition of quartzite between the two reef elevations as seen in the sidewall of a newly developed orepass underneath the stope (in supposedly de-stressed conditions)

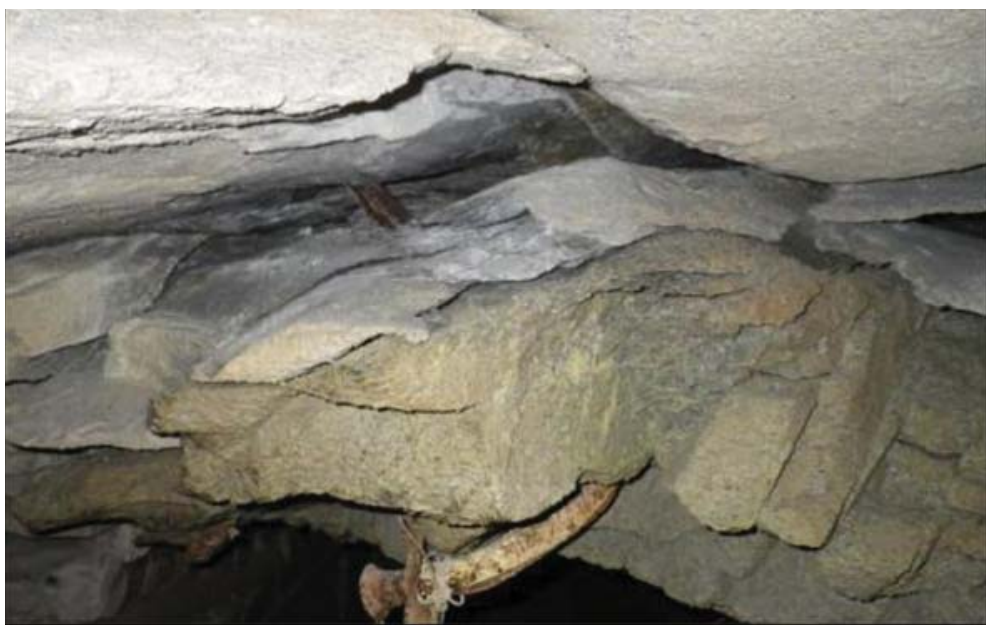

Figure 21-Unravelling of the hangingwall in the back area of the Libanon stope where the effects of the multi-reef mining could be observed. This damage can possibly be attributed to the tensile zone in the hangingwall caused by the de-stressing process 
Some rock engineering aspects of multi-reef pillar extraction on the Ventersdorp Contact Reef

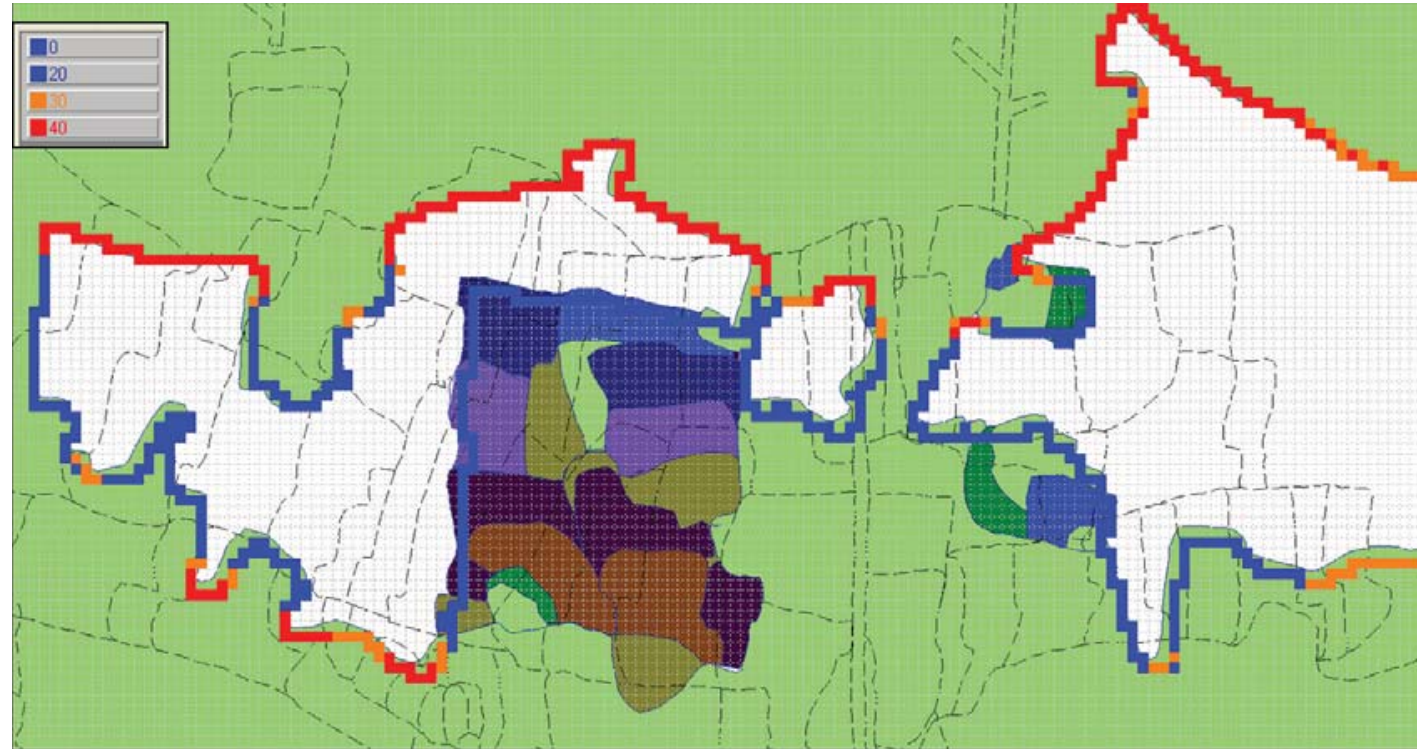

Figure 22-Sequenced layout for the modelling of VC25-23. This is on the VCR horizon and the green colour shows the VCR area that was mined previously. See Figure 13 to understand the position of these VCR blocks in relation to the larger area of mining. The outline of the Libanon Reef mining is shown by the dotted lines. The values indicated in the legend are ERR with units of $\mathrm{MJ} / \mathrm{m}$

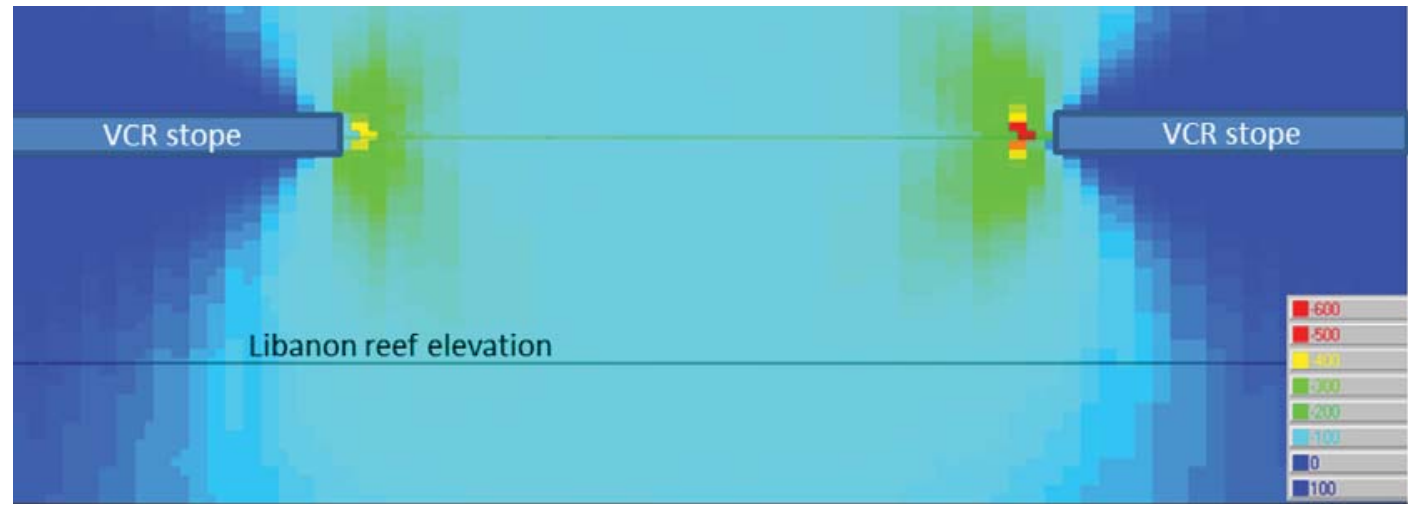

Figure 23-Contour plot of the major principal stress prior to any mining on the Libanon Reef. The unit of stress in the legend is MPa

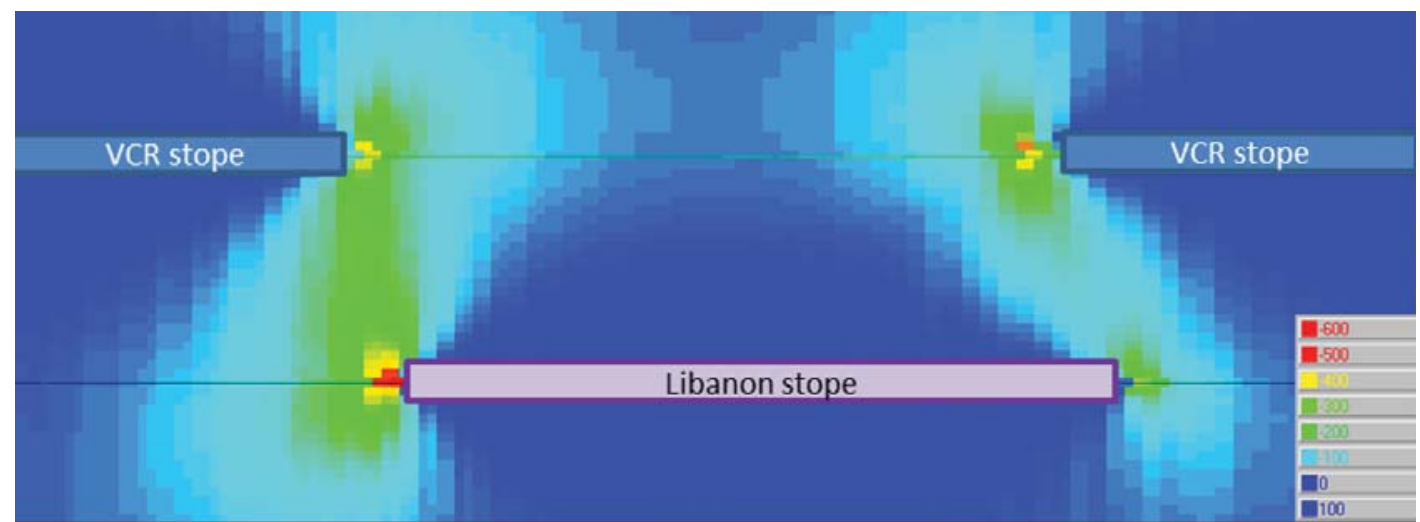

Figure 24-Contour plot of the major principal stress during the understoping. The unit of stress in the legend is MPa 


\section{Some rock engineering aspects of multi-reef pillar extraction on the Ventersdorp Contact Reef}

The MINSIM code was used to conduct a numerical study of the area shown in Figure 13. As an example, the simulated ERR values on the VCR reef horizon are shown in Figure 22. Note the high values of ERR (red blocks) on the edges of these pillars not yet understoped by the Libanon Reef. Sections were also taken in areas where the VCR pillars was being understoped by mining on the Libanon Reef. Examples of this modelling are shown in Figures 23 and 24. Note that the zones of high major principal stress between the reefs were also indicated with this modelling (Figure 24).

\section{Conclusions}

This work investigated some rock engineering aspects of remnants being understoped on a secondary reef horizon. Numerical modelling was done using the TEXAN displacement discontinuity code. An analysis of the stress evolution in the middling between two reef horizons indicated that a zone of high major and low minor principal stress develops between the two reefs. This indicated a high risk of violent shear failure and this should be considered when assessing the risk of multi-reef mining. Some pillars were nevertheless successfully understoped in the past and some mechanism must therefore exist to prevent violent failure from occurring. This study investigated one possible mechanism.

An 'extended' ERR concept proved to be useful for investigating this problem as it allows for a dissipative component to be incorporated in the criterion. Of particular interest was the effect of shear on discontinuities as this can be explicitly simulated in the TEXAN code. The study indicated that the stope convergence and the various energy components are affected by the presence, position, and properties of a bedding plane. The energy solutions are complex and sometimes counterintuitive, and care should therefore be exercised when modelling specific cases. The modelling was nevertheless valuable for indicating that energy dissipated on weak layers, such as bedding planes, may reduce the risk of violent failure in a multi-reef mining scenario. Additional work is required to investigate whether crushing on the reef plane plays a prominent role when mining these multi-reef remnants. A key objective of future work will be to determine which reef types will be problematic during the under- or overstoping process.

\section{Acknowledgements}

This work formed part of the MSc study by the principal author at the University of the Witwatersrand. The authors wish to thank Professor John Napier for his assistance with the energy calculations in the TEXAN code. The numerical modelling of the idealized geometry also formed part of the mining rate studies for the Harmony Rock Engineering Chair at the University of Pretoria.

\section{References}

DeIST, F.H., Georgiadis, E., and MoRIs, J.P.E. 1972. Computer applications in rock mechanics. Journal of the South African Institute of Mining and Metallurgy, vol. 72. pp. 265-272.

Du PLESSIS, A.P. and TALU, M.S. 1997. Ventersdorp Contact Reef pillar extraction at Libanon - a division of Kloof Gold Mining Company Limited.
Proceedings of the First Southern African Rock Engineering Symposium (SARES 1997). South African National Institute of Rock Engineers. pp. $459-466$.

DURRHEIM, R.J. 1997. Site response to rockbursts. Proceedings of the 1997 SIMRAC Symposium, Welkom. Safety in Mines Research Advisory Committee, Johannesburg.

HusTRULID, W.A. 2001. Underground mining methods: Engineering Fundamentals and International Case Studies. Society for Mining, Metallurgy \& Exploration, Littleton, CO.

JAger, A.J. and Ryder, J.A. 1999. A Handbook on Rock Engineering Practice for Tabular Hard Rock Mines. Safety in Mines Research Advisory Committee (SIMRAC), Johannesburg.

MALAN, D.F. and NAPIER, J.A.L. 2018. Reassessing continuous stope closure data using a limit equilibrium displacement discontinuity model. Journal of the Southern African Institute of Mining and Metallurgy, vol.118, no. 3 . pp. 227-234

MARITZ, J.A. 2014. The presence of shear stresses in pillars and the effect on factor of safety in a room-and pillar layout. Journal of the Southern African Institute of Mining and Metallurgy, vol. 114. pp. 1049-1055.

Maritz, J.A., Malan, D.F., and PiPer, P.S. 2012. Estimating pillar stresses in complex multi-reef layouts. Proceedings of the Second Southern Hemisphere International Rock Engineering Symposium, Sun City, South Africa, 14-17 May 2012. pp. 125-143.

NAPIER, J.A.L. 1991. Energy changes in a rockmass containing multiple discontinuities. Journal of the South African Institute of Mining and Metallurgy, vol. 91. pp. 145-157.

NAPIER, J.A.L. and MALAN, D.F. 2007. The computational analysis of shallow depth tabular mining problems. Journal of the South African Institute of Mining and Metallurgy, vol. 107. pp. 725-742.

NAPIER, J.A.L. and MALAN, D.F. 2008. Numerical simulation of a multi-reef tabular mining layout in a South African platinum mine. Proceedings of the First Southern Hemisphere International Rock Mechanics Symposium. Potvin, Y., Carter, J., Dyskin, A., and Jeffrey, R. (eds). Australian Centre for Geomechanics, Perth.

NAPIER, J.A.L. and MALAN, D.F. 2012. Simulation of time-dependent crush pillar behaviour in tabular platinum mines. Journal of the Southern African Institute of Mining and Metallurgy, vol. 112. pp. 711-719.

NAPIER, J.A.L. and MaLAN, D.F. 2014. A simplified model of local fracture processes to investigate the structural stability and design of large-scale tabular mine layouts. Proceedings of the 48th US Rock Mechanics / Geomechanics Symposium, Minneapolis, USA. American Rock Mechanics Association, Alexandria, VA.

Plewman, R.P., Deist, F.H., and OrtLePp, W.D. 1969. The development and application of a digital computer method for the solution of strata control problems. Journal of the South African Institute of Mining and Metallurgy, vol. 69. pp. 33-44.

RIEMER, K.L. and DuRRHEIM, R.J. 2011. Mining seismicity in the Witwatersrand Basin: Monitoring, mechanisms and mitigation strategies in perspective. Journal of Rock Mechanics and Geotechnical Engineering, vol. 4, no. 3. pp. 228-249

RYDER, J.A. and JAGER, A.J. 2002. A Textbook on Rock Mechanics For Tabular Hard Rock Mines. Safety in Mines Research Advisory Committee (SIMRAC), Johannesburg.

RYDER, J.A. and NAPIER, J.A.L. 1985. Error analysis and design of a large-scale tabular mining stress analyser. Proceedings of the 5th International Conference on Numerical Methods in Geomechanics, Nagoya, Japan. CRC Press. pp. 1549-1555

SALAmon, M.D.G. 1984. Energy considerations in rock mechanics: fundamental results. Journal of the South African Institute of Mining and Metallurgy, vol. 84. pp. 233-246.

VAN DER MERWE, J.N. and MADDEN, B.J. 2002. Rock Engineering for Underground Coal Mining. South African Institute of Mining and Metallurgy, Johannesburg. 